\title{
Impacts of urban-rural income gap on consumer demand in China
}

\author{
Jiawu Gan \\ International Business School \\ Yunnan University of Finance and Economics \\ Kunming, China \\ 38585206@qq.com
}

\begin{abstract}
Under the background of China's current economic development, this paper brings forward the urgency for discussing the impact of China's urban-rural income gap (IG) on Residents' consumption demand (CD), and summarizes and describes the research methods and research ideas of the problem. First of all, the IG and consumption of urban and rural residents(URR) in China are analyzed quantitatively, then the Keynes' absolute income hypothesis was used as the basis of theoretical research. Then by constructing time series and establishing co-integration model to verify the specific mechanism of IG on consumption, and according to the time phase changes to focus on analysis. Finally, it is concluded that the widening of IG between URR in China is not conducive to the growth of CD, and the influence coefficient of IG on consumption in the early stage is smaller than that of IG on consumption in the later stage of economic development. Therefore, this paper proposes to deepen the reform of income distribution, improve social security and other social systems, increase the income of rural residents (IRR), reduce the IG between urban and rural areas(URA), and promote the progress of urbanization, taking into account the actual situation in China. Rational use of labor force transfer to narrow the IG between URA, thus promoting rapid economic development in China.
\end{abstract}

Keywords-urban-rural income gap; consumption demand; average consumption propensity; marginal consumption propensity

\section{INTRODUCTION}

Since the economic reform and opening up (ROU) policies had been introduced, the IG between URA has also been expanding with the rapid economic development of China. This widening IG is closely related to Chinese government's strategy of catching up and surpassing its economy. Before the economic reforming and opening up to the outside world, China implemented the planned economic system. This stalemate in the distribution of egalitarianism under this planned economy has not only dampened the enthusiasm of workers in production, hindered the economic development but also affected the improvement of living standards of residents, which requires being broken down to achieve common prosperity. The economic structure of developed countries at that time showed that the high proportion of heavy industry marked the country's relatively high level of economic development and strong economic strength. Under that background, the key to establishing a comparatively complete industrial structure in China is the heavy industry. In an economic body with a massive poverty-stricken rural population, the government giving top priority to the development of light industry may encounter the problem of insufficient market demand and the accumulation of capital necessary for industrialization. However, the heavy industry can be self-service and self-cycling, which will not be constrained by this condition. Thus, in 1985, former general secretary Deng Xiaoping proposed the implementation of the policy of prior prosperity and common prosperity that "When some people and regions become prosperous first, others will be brought along. Thus, common prosperity of the entire population will be gradually achieved." This "catching-up and surpassing" strategy in economic development reflects the desire that China yearned for narrowing the economic gap with the developed industrialized countries at the time and surpassing the requirements of the stage of industrial development.

Up to now, the "catching-up" strategy of the Chinese government has completed the corresponding goals. China's economy is now the second largest economy in the world. By the time of 2015, China's primary, secondary and tertiary industries accounted for $8.88 \%$ of the total industrial output, $40.93 \%$, and $50.19 \%$ respectively. With the economic development and optimization of industrial structure, the living standards of inhabitants in URA have been improved significantly. The data shows that the per capita disposable income of urban residents (DIUR) in China increased from 343.4 RMB in 1978 to $31790.3 \mathrm{RMB}$ in 2015 , with an average AGR(AGR) of $13.40 \%$. The per capita net IRR increased from 133.6 RMB in 1978 to $10772.0 \mathrm{RMB}$ in 2015, with an average AGR of $12.97 \%$. The per capita consumption of urban residents increased from 311.6 RMB in 1978 to $21392.4 \mathrm{RMB}$ in 2015, with an average AGR of $12.47 \%$; per capita consumption of rural residents increased from 116.1RMB in 1978 to $9222.6 \mathrm{RMB}$ in 2015 , with the average AGR of $12.92 \%$.

Meanwhile, the urban-rural IG has been increasingly widened. Besides, people's consumption has attracted growing attention. Relevant statistics from National Bureau of Statistics of China shows that the Gini coefficient has risen from 0.317 in 1978 to 0.462 in 2015, which has already surpassed the international warning threshold of 0.4 . It illustrates that China's

*Corresponding author 
income distribution is not equal and there is a critical IG. At the same time, according to 2016 Bulletin of Statistics of China, the final consumption rate in 2015 reached $51.6 \%$, of which household consumption rate only accounts for $38.0 \%$. This shows the insufficient consumer demand and depression of consumption in China. In addition, average annual GDP in China growth rate dropped from $15.97 \%$ in $1978-2011$ to $8.94 \%$ in 2011-2015. The declining GDP growth rate, comparatively low household consumption rate and severe IG may make it difficult to achieve sustainable economic growth in China.

This thesis will analyze the relationship between urbanrural income disparity and resident consumption in different stages of economic development in China. After analyzing the impact of rural-urban IG on resident consumption, this thesis will propose relevant suggestions to hopefully narrow the ruralurban IG in China, thus to enhance consuming capacity and to promote sustainable development of the economy in China.

This article will probe into the relationship between IDG and $C D$ in China. There are many factors that affect consumption. Many scholars have discussed it from different angles. It can see that the IDG does have a certain impact on CD. However, in the existing consumption theory, the relationship between the two is not clearly given. After experiencing rapid growth in the 1980s, the Chinese economy has developed from a supply-constrained economy to a demand-constrained economy. The sluggish consumer demand has become the decisive force restricting China's economic growth, and the continued widening of the IDG will not be conducive to the long-term harmonious development of China.

Therefore, from a new point of view, this paper analyzes the performance of different economic periods in the economic system transition, and tries to find out the specificity and stages. By using econometrics method to do empirical research, this paper try to find out the relationship between the urban-rural areas IG between and CD, and put forward relevant policy recommendations, hoping to promote sustained economic growth in China.

\section{METHODOLOGY}

\section{A. Introduction}

By considering the collected data results and processing the original data, this paper can find that although the valuable problems have been obtained, the data are static and can't explain the research results vividly. Therefore, this study introduces quantitative analysis and empirical analysis to discuss.

Quantitative analysis: In order to describe the IG and trend between URA in China, absolute and relative indicators are selected, and the consumption status and changing trend are described by means of average index and marginal index. And through the form of charts and quantitative analysis of both.

Empirical analysis: In order to further illustrate the impact of urban-rural IG on the CD of residents, this paper will use cointegration test and Granger causality test to analyze.

\section{B. Time and Location}

The study was based on reading and studying a lot of literature. The study, which began in November 2017 to allow enough time to analyze the data, was also designed to prevent accidents and ensure flexibility.

All the data come from the China Statistical Yearbook, some of which are calculated. And two principal analyze types were used:

Quantitative analysis: In order to describe the urban-rural IG in China, the paper selects the data of the DIUR and the net IRR, and measures the level of urban-rural IG by relative and absolute indicators. Meanwhile, in order to describe the consumption status of URR in China, the paper will describe two indicators of URR' marginal consumption propensity and average consumption propensity based on the data of URR' consumption level in China.

Positive analysis: In order to further describe how the IG between URA in China has an impact on the CD of residents, this paper adopts the empirical analysis method in the analysis. Firstly, according to the analysis of the data, the model is established, and then the econometrics method is used to carry on the empirical research.

\section{Validating Key Hypotheses and Variables \\ 1) Key hypotheses}

Hypothesis one : there is a long-term and stable negative correlation between the IG between URR in China and the APC in China.

Hypothesis two :There is a long-term causality between China's urban and rural IG and the average consumption tendency of Chinese residents.

\section{2) Variables}

This paper will analyze the IG between URR and the average consumption propensity of urban residents in China. The object of study is the IG between URR in China and the average consumption tendency of Chinese residents. Therefore, this paper selects the Chinese URR' IG and the average consumption tendency of Chinese residents as the variables. Among them, the average consumption tendency of Chinese residents is explained as a variable, it represents the level of CD of Chinese URR, and the real income ratio of Chinese urban-rural residents is the explanatory variable to measure the IG between URR in China.

\section{DATA DESCRIPTION}

\section{A. Income Gap Status}

From 1956 to 1978 , because China was under a planned economic system, a distribution system based on fairness was implemented. At that time, it was mainly to protect the fundamental interests of the people. However, the development of this system led to low production efficiency in the later period, and people's enthusiasm for production declined. Laborers often have no enthusiasm and lack of creativity in their production activities. To improve the situation, mobilize the enthusiasm and enthusiasm of the people, and also improve 
the living standards of residents, the Chinese government has implemented a series of reform measures. In the system of residents' income distribution, the system of distribution based on work and multiple modes of distribution has been implemented, which has greatly improved the income level of residents. At the same time, the slogan "Get rich first and then get rich" also inspired a large number of laborers to invest in production and development. These not only changed the distribution system that was based on fairness at the time but also motivated people's enthusiasm and improved Efficiency, China's economic development and people's living standards have all changed dramatically.

With the development of ROU, China's economy has undergone a qualitative leap. China's current income distribution system has become increasingly perfect. The distribution system has gradually changed from a single planned economic system that pursues fair distribution to a market economy system. The dominant distribution system has greatly increased the income of the residents and stimulated the growth of consumption, leading to a marked improvement in the living standards of the residents. However, while the reforms have achieved fruitful results, some of the problems brought about by rapid development have been reflected. The IG between residents generated under the current distribution system has shown an expansion both within and between URA. The trend [1]. There are many aspects of the performance of the IDG change. It is generally believed that the IG will gradually expand as the economy grows, and it will have a certain impact on consumption. In order to study the impact of the urban-rural IG on the CD of Chinese residents, this chapter mainly selects the data on the income level of URR during the period of 1978-2015 in China to analyze the growth of the income level of URR in China and the URR in China. Changes in the IG, and analyze the reasons for the changes and the impact of excessive gaps.

\section{B. Consumption Level}

Consumption is the behavior and process in which people use the material and spiritual products they produce to meet their personal needs. It is an economic behavior that humans satisfy their desires with consumer goods. Consumer demand is accomplished in the market, which is influenced by the income level and the market supply. Wang and Tang (2015) [2] proposed that due to the vast differences among infrastructure construction, consumption patterns and market supply between URA in China, there are different characteristics in their consumption structure and consumption characteristics. In this part, the main purpose of this article is to compare the changes in consumer spending and propensity to consume between URR in China, reflecting the current problems in China's consumer demand. This will provide a basis for further research on the IG between URR in China.

\section{Statistical Data and Chart Comparison of Income Gap and Consumption Demand between Urban and Rural Residents in China}

Through the previous quantitative analysis of the IG and CD of Chinese URR, it can see that the uneven distribution of income does have an impact on $\mathrm{CD}$, but the functional relationship between the two cannot be given. In order to further explore the functional relationship between the two, this section will study this.

\section{Summary of Data}

This section mainly uses data and charts to conduct a detailed quantitative analysis of the IG between URA in China and the current state of consumer demand. It has been found that China's domestic income distribution pattern has undergone enormous changes since 1978. The IG between URR in China has gradually expanded, and there have been periodic fluctuations. At the same time, from the data, it has been found that the consumption situation of URR has also undergone tremendous changes, and there has also been a significant gap in the proportion of consumption between URR

Judging from the IG, the current IG between Chinese residents is high, and the widening of the nation's residents' IG is mainly manifested in the widening IG between URA. From the perspective of data and charts, the pattern of China's income distribution has greatly differed from the initial stage of economic reform, and it is also clearly different from the situation in the late 1980s. The IG between URA is gradually expanding, and the IG has shown a stage of expansion. Sexual characteristics. This phased feature is a unique feature of China's ROU. It is both the result of economic reforms and the price paid by economic reforms. China's unique institutional transition and institutional changes cannot be learned from other countries. Stones cross the river and gradually improve.

According to the analysis of the consumption situation of Chinese residents, the consumption rate of Chinese residents has decreased significantly since the ROU. The decline in the household consumption rate is related to the decrease in the proportion of the income of Chinese residents to the national income on the one hand, and to China since the ROU on the other hand. The decline in the consumer's propensity to consume has a significant relationship. Consumer demand is the main driving force for the country's economic growth. If consumer demand is insufficient, it will undoubtedly hinder economic growth. Therefore, if want to maintain sustained, stable, and rapid economic growth, that must shift the foothold to expand domestic consumption. Leading demand pulls up. However, from the perspective of various data and indicators, China has shown symptoms of insufficient consumer demand.

This article analyzes from a new perspective to study whether the expansion of the IG inhibits the growth of consumer demand. It seems that there is no connection between the two, but there is a significant correlation between the two. Based on the analysis of the IDG between Chinese residents and the analysis of the resident's consumption, it can be seen that:

As the income disparity between URR widens, the average propensity for consumption of residents gradually decreases, which has a negative impact on the overall domestic consumer demand. There may be a negative correlation between the income disparity between URR in China and the average propensity of residents. This conclusion was further validated by quantitative analysis of two areas, urban and rural. 
With the widening IG between URR, the consumption gap has continued to expand; there may be a positive correlation between the two. Quantitative analysis of URA also verifies this conclusion.

Within a certain range, the IG between URR will have a positive effect on the per capita consumption level of URR. After exceeding the reasonable range, the IG between URR will have an inhibitory effect on the per capita consumption level of residents.

Based on the above analysis results, this paper believes that the current widening urban-rural IG in China has a significant negative impact on the consumer demand.

It should be noted that the collected data and data come from the "China Statistical Yearbook" of the past years, but there are still some data that may have errors due to the different statistical standards in different periods. After the late identification and sorting of data, these deficiencies are well circumvented. Therefore, the data presented in the paper are reliable.

\section{DATA ANALYSIS}

\section{A. Selection of Variables and Data and Setting of Models}

The gap between the IDG between URR in China and the average consumption propensity of residents should be analyzed. The object of study is the IDG between URR in China and the average consumption propensity of Chinese residents. This chapter selects China's average consumer propensity (APC) as an explanatory variable, which represents the level of consumer demand of URR in China. This chapter uses APC, that is, the $\bar{C}$ in the preceding article indicates that the average consumption tendency of Chinese residents, $C$ is total consumer spending by Chinese residents, $Y$ is total disposable income for Chinese residents. The formula can be expressed as: ${ }^{A P C}=\frac{C}{Y}$

The Chinese URR' income ratio is selected as the explanatory variable to measure the IG between URR in China. The formula is: Chinese urban and rural residents' income ratio=per capita disposable income of urban residents in China/ per capita net income of Chinese rural residents.

According to the data in the China Statistical Yearbook, the data of urban per capita disposable income and rural per capita net income from 1978 to 2015 are combined. The IG between URA in China and the average propensity of Chinese residents are calculated using the formula.

\section{B. Stationary Test of Model Variables}

According to the relevant theory of econometrics, if linear regression is performed directly on two variables, there is often a phenomenon of "pseudo-regression," that is, although there is a certain amount of relationship between variables, in fact, the two are not related to the phenomenon. To avoid the "pseudoregression" problem, it is usually necessary to test the stability of relevant variables before performing regression analysis [3]. This paper uses ADF (Augmented Dickey-Fuller) test to determine whether the time series of Chinese URR' IG and APC are stable, and determine their single integer orders.

The original assumption of the ADF test is that there is at least one unit root in the time series, which means that the time series is not stable. If the hypothesis is that there is no unit root in the time series, the time series is a stationary series [4]. This paper uses software Eviews 7.2 to test the stability of the twotime series data of Chinese URR' income inequality and Chinese URR' average APC in Table 3, using ADF to test the original and differential variables analyzed. The results are shown in figure 1.

\begin{tabular}{|c|c|c|c|c|c|c|}
\hline \multicolumn{7}{|c|}{ Unit root test result } \\
\hline Variable & $\begin{array}{c}\text { Type of } \\
\text { inspection(C,T) }\end{array}$ & ADF & $\begin{array}{c}\mathbf{1 0 \%} \\
\text { critical } \\
\text { value }\end{array}$ & $\begin{array}{c}\mathbf{5} \% \\
\text { critical } \\
\text { value }\end{array}$ & P value & Result \\
\hline URR & $(\mathrm{C}, 0)$ & -2.65 & -3.20 & -3.545 & 0.265 & Unsteady \\
\hline$\triangle$ URR & $(\mathrm{C}, 0)$ & -8 & -1.611 & -1.95 & 0 & Steady \\
\hline APC & $(\mathrm{C}, 0)$ & -2.28 & -3.2 & -3.54 & 0.4344 & Unsteady \\
\hline$\triangle \mathrm{APC}$ & $(\mathrm{C}, 0)$ & -11.57 & -1.61 & -1.95 & 0 & Steady \\
\hline
\end{tabular}

Fig. 1. Unit root test result

According to the test results, both time series data of urbanrural IGs and average consumption propensities in China have at least one unit root, i.e., non-stationary sequences. After performing first-order differential processing on the two variables, the stationarity test was performed. As a result, it was found that the first-order difference sequences of the two variables are all stable sequences, that is, these variables are first-order monolithic sequences. Therefore, the conditions for the co-integration test can be met, and the gaps and average incomes of Chinese URR can be satisfied. Consumers tend to co-integrate two-time series data.

\section{Co-integration Test}

The co-integration test is an econometric method used to test whether there is a long-term stable relationship between variables. The existence of a co-integration relationship is a conditional requirement. It is only possible to study multiple variables of the same order in a single integer sequence. There is a co-integration relationship, so the unit root test of the variables must be performed first when conducting the cointegration test [5]. According to the previous conclusion, this paper uses the Johansen test to test the long-term equilibrium relationship between the two. .The results of co-integration analysis are sensitive to the selection of delay length, therefore, the lag order should be determined before the test is carried out.

\section{1) Determination of lag order}

The Johansen multivariable system maximum likelihood estimation (MLE) method is used to test whether there is a cointegration relationship between variables.Because of the limited sample size of the time series, only by maintaining a relatively reasonable degree of freedom can the parameters in the model be able to explain the impact to the maximum extent.At the same time, in order to eliminate the autocorrelation of the error term, it is necessary to eliminate the auto-correlation of the error term,using the AIC,SC information criterion, LR statistics and other testing methods as 
the criteria for selecting the optimal lag order, finally, according to the optimization principle, the delay order of VAR model for co-integration test is determined to be 1 . As shown in figure2.

\begin{tabular}{|c|c|c|c|c|c|c|}
\hline \multicolumn{7}{|c|}{ Selective test of VAR model lag phase } \\
\hline Lag & Log L & LR & FPE & AIC & SC & HQ \\
\hline 0 & 106.9345 & NA & $7.15 E-06$ & -6.172617 & -6.082831 & -6.141997 \\
\hline 1 & 114.611 & $13.99842^{*}$ & $5.76 \mathrm{e}-06^{*}$ & $-6.388884^{*}$ & $-6.119527^{*}$ & $-6.297026^{*}$ \\
\hline 2 & 117.29 & 4.570074 & $6.25 \mathrm{E}-06$ & -6.311179 & -5.862249 & -6.158081 \\
\hline \multicolumn{7}{|c|}{ Notice: * represents the optimal lag. } \\
\hline
\end{tabular}

Fig. 2. Lag Order Test Results

As can be seen from Table 2, the three information standards of FPE, AIC and HQ agree that an unconstrained VAR(1) model should be established. That is, the optimal lag time of unconstrained VAR model should be 1, and the effect of co-integration test is the best.

\section{2) Johansen co-integration regression test}

For multivariate, there may be multiple co-integration relations. Johansen co-integration test is a method of testing regression coefficients based on VAR model proposed by Johansen in 1998. It has a good performance in testing multivariable co-integration relations. The characteristic root trace test is used to test the Johansen co-integration relationship.

\begin{tabular}{|c|c|c|c|c|}
\hline \multicolumn{5}{|c|}{ Johansen Co-integration test result } \\
\hline $\begin{array}{c}\text { Null } \\
\text { hypothesis } h_{0}\end{array}$ & $\begin{array}{c}\text { Characteristic } \\
\text { value }\end{array}$ & $\begin{array}{c}\text { Trace test } \\
\text { statistic }\end{array}$ & $\begin{array}{c}\text { Critical value at } \\
10 \% \text { significant } \\
\text { level }\end{array}$ & $P$ value \\
\hline \begin{tabular}{|c|} 
No \\
co-integration \\
relationship \\
\end{tabular} & 0.328999 & 23.15559 & 13.42878 & 0.0029 \\
\hline $\begin{array}{c}\text { At most } 1 \\
\text { co-integration } \\
\text { relation }\end{array}$ & 0.245773 & 9.590119 & 2.705545 & 0.002 \\
\hline
\end{tabular}

Fig. 3. Johansen co-integration test result

\begin{tabular}{|c|c|c|}
\hline Co-integration relation & $\begin{array}{c}\text { Logarithmic likelihood } \\
\text { value }\end{array}$ & 115.1367 \\
\hline \multicolumn{3}{|c|}{ Standardized co-integration coefficient (standard error in parentheses) } \\
\hline$\triangle \mathrm{APC}$ & \multicolumn{2}{|c|}{$\triangle \mathrm{URR}$} \\
\hline \multirow{2}{*}{1} & \multicolumn{2}{|c|}{-0.4737} \\
\hline & \multicolumn{2}{|c|}{$(0.12683)$} \\
\hline \multicolumn{3}{|c|}{ Standardized co-integration equation } \\
\hline & $\triangle \mathrm{APC}=-0.4737^{*} \triangle \mathrm{UR}$ & \\
\hline
\end{tabular}

Fig. 4. Standardized co-integration coefficient and co-integration equation

According to the results of figure 3 and figure 4 cointegration test, based on the output, establish a co-integration equation for the income ratio of URR in China and the APC:

$$
\triangle \mathrm{APC}=-0.4737 * \triangle \mathrm{URR}
$$

From the co-integration equation, we can see that from 1978 to 2015, there is a long-term and stable negative correlation between the Chinese URR' income ratio and the APC (APC) of Chinese residents. In addition, if the Chinese
URR' income ratio changes by 1 unit, the APC will reverse 0.4737 units.

\section{Granger causality test}

Through the results of the above co-integration test, it is found that there is a long-term stable equilibrium relationship between the IDG between URA in China and the average consumption trend of residents. In order to further analyze the impact of the IDG between URA in China on the average consumption trend of residents, Granger causality test can be conducted.

The Granger causality test can be used to determine whether there is a causal relationship between economic variables and the direction of its impact. The results are shown in figure 5 .

\begin{tabular}{|l|c|c|c|}
\hline \multicolumn{3}{|c|}{ Pairwise Granger Causality Tests } \\
\hline Sample: $1978-2015$ & & \\
\hline Lags: 1 & Obs & F-Statistic & Prob. \\
\hline Null Hypothesis: & 36 & 1.74829 & 0.1908 \\
\hline APC does not Granger Cause URR & & 2.60427 & 0.0901 \\
\hline URR does Granger Cause APC
\end{tabular}

Fig. 5. Granger causality test results

Table 5 shows that at a significant level of $10 \%$, Chinese URR' income ratio is the Granger cause of APC change. APC is not the Granger cause of Chinese URR' income ratio change. That is, the urban-rural IG in China will have an impact on the average consumption tendency of the residents, and it is also the reason for the change of the consumption tendency of the residents.

Combined with the results of co-integration test, the economic significance of the results shows that the explanatory variable China's URR' income ratio coefficient is negative, indicating that the direction of the Chinese household's average consumer propensity (APC) changes by the explanatory variable is opposite to the independent variable. There is a significant negative correlation between the two.

The practical significance of the result is that if the IG between URR in China continues to widen, this part of the increased income will be more tilted toward urban residents, and the urban residents' consumption tends to become smaller under the influence of the law of diminishing MPC. At the same time, rural residents who have a higher propensity to consume have not achieved the corresponding income from consumer demand. Inequality in income will increase the imbalance in consumption. This verifies that the widening IG between URR in China has led to a decrease in the average consumer propensity to consume, further inhibiting the overall increase in consumer demand.

\section{E. Summary}

In the above analysis methods using co-integration test and Granger causality test to deal with non-stationary variables, the impact of Chinese residents' IDG on the average consumption propensity of Chinese residents was analyzed. From the empirical results, the following conclusions can be drawn: 
Through the co-integration test on the average consumption propensity of Chinese residents and the IG between URA in China, we found that there is a long-term stable relationship between variables, which means that the APC has a stable internal impact with the IG. The mechanism, and the IG between URR in China changes by 1 unit, the average consumption propensity of residents will be reversed by 0.4737 units.

As can be seen from the Granger causality test results, the IG between URA in China is the reason for the change of consumption tendency. This shows that the IDG of Chinese residents will have a certain impact on the average consumption trend of residents.

Through empirical analysis of the impact of the above IG on consumer demand, it can be concluded that there is indeed a relationship between the IG between Chinese residents and consumer demand, and the widening IG will have a negative impact on consumer demand, and it is also an important cause of the lack of consumer demand.

\section{CONCLUSION}

\section{A. Deepening Reform of Income Distribution}

From the previous analysis, we can see that the urban-rural IG has a huge effect on both urban and rural consumption levels. Therefore, it is of great significance to narrow the IG between URR in order to increase consumer demand and further increase China's total domestic consumption. The income distribution system has a direct impact on the income distribution of residents and it is related to the vital interests of the people. At present, China still has many irrational places in the income distribution system. These unsound places have kept the IG of Chinese residents high. Therefore, it is very necessary to deepen and reform China's income distribution system to further reduce the IG between residents and promote the growth of domestic demand.

\section{B. Increase the Income of Rural Residents and Narrow the Income Gap between Urban and Rural Areas}

Regarding household consumption, from 2010 to 2013, relative to urban residents, the growth rate of per capita consumption of rural residents has always been in a leading position. All kinds of data show that China's rural consumer market still has much space to explore. At the same time, it should be noted that the biggest obstacle to rural consumption is that rural residents' income has not kept up with the expected income. The state should pay more attention to raising the importance of IRR and give full play to the role of many parties. Only in this way can the consumption needs and desires of rural residents be met as much as possible, and rural consumption can truly make use of the soft landing of China's economy. The role of cushions is to achieve social equity as soon as possible.

\section{Promote the Progress of Urbanization and Make Rational use of Labor Force Transfer to Narrow the Income Gap between Urban and Rural Areas}

In the process of urbanization in rural areas, there is a gap between URR at the starting point of income, which inevitably leads to a certain degree of income imbalance. However, the process of urbanization, as an important development path in the historical transformation of mankind, has great advantages, and it is also the only way to realize China's transformation from a big agricultural country to a modernized country ( $\mathrm{Xu}$ and $\mathrm{Li}, 2016)$. In this regard, in the process of realizing the transformation of rural urbanization, we must pay particular attention to the dual goals of promoting urbanization and narrowing the urban-rural IG, and rationally utilizing the reasonable transfer of rural labor to effectively steadily advance China's urbanization.

\section{REFERENCE}

[1] M. Chen, The Impact Of Income Distribution Gap On Consumption Demand Of Urban Residents In China Based On Theil Index. Doctoral Dissertation, Jilin University.2011.

[2] Z. S. Chen, On income Distribution in Reform and Development: Is there a polarization in China.Beijing: Economic Science Press.2012.

[3] J. P. Fan, J. P., and S J. Xiang, S. J., (2009). The Influence Of The Dual Social Structure Of Urban And Rural Population On The Consumption Rate In China. Managing The World(5),pp.35-38.2009.

[4] L. S. Gao, and L. Deng, Empirical Analysis Of The Relationship Between Residents' Consumption Rate And Income Distribution Structure And Distribution Gap. Consumer Economy(4),pp. 3-6.2009.

[5] Z. Y. Jin, The Income Distribution Of Residents In China And Its Influence On Consumption. Doctoral Dissertation, Jilin University.2011.

[6] J. L. Li, and X. F. Mo, Income Distribution Gap, Consumption Demand And Economic Growth Of Urban Residents. Statistics And Decision Making(10),pp. 95-97.2006

[7] P. Li, The Influence Of Urban Residents' Income Distribution Gap On Consumption Demand In China. Doctoral Dissertation, Finance And Economics University Of Jiangxi.2010.

[8] Z. N. Li, and A. Z. Ye, Higher Econometrics. Beijing: Tsinghua University Press.2007.

[9] Y. Liao, Y. Analysis Of The Mechanism Of The Influence Of Income Gap Expansion On China's Residents' Consumption Shortage. Chinese Collective Economy(34),pp. 26-27.2009.

[10] A. C. Liu, and Y. F. Li. Empirical Analysis Of Income Gap Between Urban And Rural Residents Based On Theil Index. Business, (16),pp.187-188.2013. 